\title{
Comparison of different methods for activation of ordinary Portland cement-slag mortars
}

\author{
Fathollah Sajedi, Hashim Abdul Razak
}

Introduction

In this experimental work, mechanical, thermal, and chemical methods have been used to improve the compressive strength of OSMs. All three methods can be used to activate the potential reactivity of cement constituents.

The mechanical activation is used to increase the specific surface area of the constituents and thus accelerates the hydration rate. Many results indicate that the early strength of a hardened cement paste is directly proportional to the fineness of the cement, but fineness cannot contribute to later-age strength. In contrast, excessively high fineness may increase the water requirement and cause a reduction in later strength gain. In general, increased fineness results in better strength development, but in practice, fineness is limited by economic and performance considerations and factors such as setting time and shrinkage [1]. For better performance, the fineness of GGBFS must be greater than that of cement [2]. At the same time, the requirement to increase fineness reduces productivity and consumes more energy. Prolonged grinding not only increases the surface area of a material, but also the number of imperfections or active centers which exist at the edges, corners, projections and places where the inter-atomic distances are abnormal or are embedded with foreign atoms. These centers are in a higher energy state than in the normal structure. The more of these centers, the faster the rate of reactivity. Millers and Oulton (1970) observed that percussive dry grinding can cause obvious crystal distortion of kaolinite. It was also recently found that impaction and friction milling of high alumina cement alters its crystallinity and notably modifies its hydraulic behavior.

A strength test on 22 pozzolans (Chatterjee and Lahiri, 1967) indicated no general correlation between the compressive strength of different materials (at 28 or 60 days) and surface area (either by Blain or BET method). However, it was stated that strength increases as fineness increases, for a single material. Different pozzolans have different quantities and nature of reactive components. It 
cannot be expected that a unique relationship exists between reactivity and surface area for all pozzolans. Prolonged grinding of natural pozzolan also consumes extra energy and reduces grinding productivity [3]. It has been reported [4] that for each $10 \mathrm{~m} 2 / \mathrm{kg}$ increasing in Blain fineness, cost of grinding will be increased by about $10 \%$. Elevated temperature curing needs additional equipment and is usually suitable for precast products. It also consumes a great amount of energy. Hydrated mortars and concretes can reach their maximum strength within several hours through elevated temperature curing. However, the ultimate strength of hardened mortars and concretes has been shown to decrease with curing temperature. Variations of mortar and concrete under high temperature are mainly the result of two different mechanisms. One is the variation of material properties of the constituent phases under high temperatures, and the other is the transformation of constituent phases under different temperatures. Therefore, the property of mortar and concrete under high temperatures must be studied from both a mechanical and chemical point of view [5].

The chemical activation refers to the use of some chemicals to activate the potential reactivity of cementitious components.

Alkali-GGBFS is a typical, successful example of chemical activation. GGBFS shows little cementitious properties; nevertheless, it gives very high strengths in the presence of chemical activators such as $\mathrm{Na}_{2} \mathrm{SiO}_{3}, \mathrm{NaOH}$, and $\mathrm{Na}_{2} \mathrm{CO}_{3}$. The activator(s) can be added during the milling of cement, or can be dissolved in the mixing water and added during mixing of mortars and concretes. The technology is very simple and does not need extra equipment. However, in chemical activation method there is an important reality that it cannot be used every activator to activate every type of slag, and then for better performance by chemical activators it needs to have many tests and materials for determination of the best activator. This is an improper point in chemical activation method.

The objective of the current paper is to compare the efficacy of three activation methods, as measured by strength development and initial and ultimate compressive strengths.

\section{Research significance}

It is known that a lot of slag is produced in the steel-iron industry every year, throughout the entire world. If some means of consumption for these by-product materials can be found, it would help in terms of being environment friendly and also provide significant economic benefits. Moreover, the results of several researches have shown the use of the replacement materials in mortars and concretes has improved durability, which has vital 
significance for the structures built in aggressive environments, such as those in marine structures, such as big tunnels and bridges with long life spans. However, there is a problem in the use of the materials with initial hydration being lower than OPC and mortars and concretes having low early strengths. There are several ways of resolving this problem; including using mechanical, thermal, and chemical methods of activation, which is precisely the main purpose of this study.

3. Experimental procedure

3.1. Properties of materials

The properties of the materials have been used in the study are as follows.

3.1.1. Cement

The cement used in all mixes was OPC. ASTM C-109-99 was used for determination of the compressive strength of hydraulic cement mortars, by use of $50 \mathrm{~mm}$ sided cube specimens. The specific gravity of cement used is by about 3.14. Based on particle size analysis (PSA) tests, the specific surface area (SSA) for OPC was determined to be $1893.9 \mathrm{~m} / \mathrm{kg}$. The chemical compositions of OPC used in this research have been determined by the testing method " $X$-ray fluorescence spectrometry (XRF)". The compositions of OPC are given in Table 1.

3.1.2. Slag

The specific gravity of the slag is approximately 2.87 , with its bulk density varying in the range of $1180-1250 \mathrm{~kg} / \mathrm{m} 3$. The color of ground granulated blast furnace slag (GGBFS) is normally whitish (off-white). Based on PSA tests, the SSA for GGBFS has been determined at $3597.2 \mathrm{~m} / \mathrm{kg}$. It can be seen that SSAslag $=1.90 \_$SSAoPC, which means that particles of slag are $90 \%$ finer than that of OPC. The compositions of slag are given in Tables $4 \mathrm{a}$ and $4 \mathrm{~b}$. As with all cementing materials, the reactivity of the slag is determined by its SSA. Based on the definition of slag activity index (SAI) in ASTM C989 [5], it can be seen that SAI = (SP/P) _ 100, where; SP $=$ average compressive strength of slag-reference cement mortar cubes; $\mathrm{P}=$ average compressive strength of reference cement mortar cubes. Both compressive strengths are in MPa. Based on this definition, the slag used in the tests is classified into Grade 120 A result calculation is shown in the bottom of Table 1.

\subsubsection{Aggregates}

The fine aggregates used in the mixes are graded silica sands with specific gravity, fineness modulus (FM) and water absorption (BS812: clause 21) $2.68 \%, 3.88 \%$ and $0.93 \%$, respectively. The maximum size of aggregate is $4.75 \mathrm{~mm}$. The PSA of the fine aggregates is given in Table 2 , and the grain size distribution diagram is drawn in Fig. 1.

3.1.4. Super plasticizer

In order to have appropriate consistency with low a W/B ratio, super plasticizer (SP) is required to be used. The SP used in this investigation is Rheobuild 1100 . The specific gravity of SP is approximately 1.195 , is dark brown in color, with a $\mathrm{pH}$ in the range of 6.0-9.0. The consumed content of SP in the mortar depends on the replacement level of slag. Rheobuild 1100 is a chloride-free product. Meets ASTM C-494.

The basic components are synthetic polymers which allow mixing water to be reduced considered. The dosage of R1100 generally varies from 0.8 to $1.2 \mathrm{l} /(100 \mathrm{~kg})$ of cement. Other dosages may be recommended in special cases according to specific job conditions. It is compatible with all cements and admixtures meeting ASTM and UNI standards. 
The water used in all mixes was potable water in pipeline of the lab. It was assumed that the specific gravity of the used water is about $1 \mathrm{~g} / \mathrm{cm} 3$.

3.1.6. Activators

Chemical reagents $\mathrm{NaOH}, \mathrm{KOH}$, and $\mathrm{Na}_{2} \mathrm{SiO}_{3}, \mathrm{nH}_{2} \mathrm{O}$ were used as alkaline activators. The dosage of alkaline activators were $2 \%, 4 \%$, and $6 \% \mathrm{Na}_{2} \mathrm{O}, \mathrm{K}_{2} \mathrm{O}$, and $\mathrm{Na}_{2} \mathrm{O}(\%$ by mass), respectively. Based on the mass of slag, these activators were dissolved into mixing water first and then added to the mixing. Some physical and chemical properties of the activators are shown in Table 3.

3.2. Mix proportions and curing

Tables $4 \mathrm{a}, 5$, and $6 \mathrm{a}$ and $6 \mathrm{~b}$ represent the mix proportions for different activation methods. In all mixes, water-binder and sand-binder ratios are 0.33 and 2.25, respectively. Silica sands were used in the mixes. At first, based on PSA, five groups of silica sand were mixed. Two min following that, cement and replacement slag were put into the mixture, followed by $3-4$ min of mixing. Mixing water was then added to the mix and mixing was continued for $5 \mathrm{~min}$, following which the required amount SP was added. Mixing was continued for 2 min before the moulds were filled with fresh mortar in two layers. Each layer was compacted with ten impacts by a rod with $16 \mathrm{~mm}$ diameter. $24 \mathrm{~h}$ after casting, the specimens were demoulded and cured proportionally in water with $23 \pm 3 \_$C or in the room temperature $27 \pm 3 \_\mathrm{C}$ and $65 \pm 18 \%$ relative humidity $(\mathrm{RH})$ until the test day.

3.3. Test and mixing procedures

3.3.1. Test for fresh mortar

In order to have appropriate consistency for each mortar mix after casting, a flow table test has been done. The range of flow amounts were between 220 and $235 \mathrm{~mm}$. The test procedure is that following casting, some mortar is put in the truncated brass cone in two layers. Each layer is compacted 10 times by a steel rod with a $16 \mathrm{~mm}$ diameter, before the cone is lifted and the mortar collapsed on the flow table. Following that, both the table and mortar are jolted 15 times in a period of $60 \mathrm{~s}$. Jolting the table enables the mortar to consequently spread out and the maximum spread, to the two edges of the table, was then recorded. The average of both records is calculated as flow $(\mathrm{mm})$. The photograph for mixture and flow table test is shown in Fig. 2.

Full text is available at :

http://www.sciencedirect.com/science/article/pii/S0950061810003090

http://ac.els-cdn.com/S0950061810003090/1-s2.0-S0950061810003090-main.pdf? tid=1f70136c-7820-11e38df9-00000aacb362\&acdnat=1389156691_598fed59ba988ef24a61b55479cb6ea7 